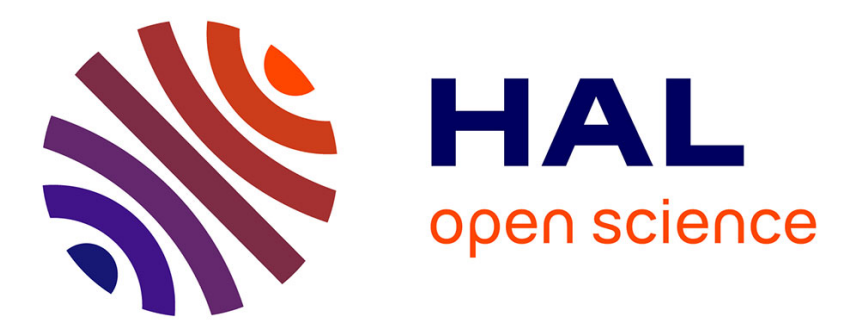

\title{
Control of the Grafting of Hybrid Polyoxometalates on Metal and Carbon Surfaces: Toward Submonolayers
}

Sarra Gam Derouich, Corentin Rinfray, Guillaume Izzet, Jean Pinson, Jean-Jacques Gallet, Fréderic Kanoufi, Anna Proust, Catherine Combellas

\section{- To cite this version:}

Sarra Gam Derouich, Corentin Rinfray, Guillaume Izzet, Jean Pinson, Jean-Jacques Gallet, et al.. Control of the Grafting of Hybrid Polyoxometalates on Metal and Carbon Surfaces: Toward Submonolayers. Langmuir, 2014, 30 (8), pp.2287-2296. 10.1021/la500067e . hal-01480767

\section{HAL Id: hal-01480767 https://hal.science/hal-01480767}

Submitted on 3 Apr 2017

HAL is a multi-disciplinary open access archive for the deposit and dissemination of scientific research documents, whether they are published or not. The documents may come from teaching and research institutions in France or abroad, or from public or private research centers.
L'archive ouverte pluridisciplinaire HAL, est destinée au dépôt et à la diffusion de documents scientifiques de niveau recherche, publiés ou non, émanant des établissements d'enseignement et de recherche français ou étrangers, des laboratoires publics ou privés. 


\section{Control of the Grafting of Hybrid Polyoxometalates on Metal and Carbon Surfaces: Toward Submonolayers.}

Sarra Gam Derouich, ${ }^{\sharp \dagger}$ Corentin Rinfray, ${ }^{\dagger}$ Guillaume Izzet, ${ }^{\dagger}$ Jean Pinson, ${ }^{\sharp}$ Jean-Jacques

Gallet, ${ }^{\ddagger}$, Frédéric Kanoufi, ${ }^{\#}$ Anna Proust* ${ }^{\dagger}$ and Catherine Combellas*\#

Sorbonne Universités, CNRS-UPMC Univ Paris 06-ESPCI.

\#UMR 7195, PECSA, 10 rue Vauquelin, F-75005 Paris. e-mail: catherine.combellas@espci.fr.

${ }^{\dagger}$ UMR 8232, IPCM, 4 place Jussieu, F-75005 Paris. e-mail : anna.proust@ upmc.fr

${ }^{\ddagger}$ UMR 7614, Laboratoire de Chimie Physique Matière et Rayonnement, F-75005, Paris.

ABSTRACT: A Keggin-type POM is attached to gold or glassy carbon surfaces by electro(chemical) or peptidic coupling. In addition to demonstrating the robust attachment of the POMs (by electrochemistry, XPS and IRRAS), the surface concentration, layer thickness and rate constant for electron transfer from the surface to the POMs have been measured. The use of such complementary techniques is mandatory to properly characterize the modified electrodes. Whatever the grafting method, experimental conditions are found to allow monolayer or submonolayer coverage. Besides covalently grafted species, additional electrostatic bonded POMs are present in the film. Cathodic polarization allows removing them to get a grafted film that is stable with time and potential, which is a requisite toward the design of molecular memories.

Keywords: polyoxometalates, diazonium salts, electrografting, peptidic coupling, electrochemistry, electron transfer 


\section{INTRODUCTION}

Polyoxometalates (POMs) are molecular metal-oxides of the early transition metals with a broad range of properties and applications. Currently, their ability to reversibly accept several electrons attracts growing attention and the potential of POM-based materials is deeply investigated for solar energy conversion ${ }^{1-4}$, molecular electronics, ${ }^{5-7}$ molecular cluster batteries $^{8}$ or as supercapacitor electrode materials, ${ }^{9}$ among others. In the field of molecular electronics, the immobilization of POMs at various surfaces is the first step toward their integration in modified field effect transistors.

The formation of POM-thin films has recently been reviewed. ${ }^{10}$ While POMs are known to spontaneously adsorb on electrodes, ${ }^{11-13}$ examples of covalent immobilization of POMs on surfaces are still scarce, although it could improve the control over the films features and their stability, especially under electrochemical polarization of the surface/electrode. ${ }^{14-16}$

Previous examples include the grafting of Lindqvist derivatives on silicon or Anderson-type POMs on gold. Targeting the use of POMs as charge storage molecules, we have also reported the covalent electrografting of functionalized Keggin-type POMs with pending alkyne or diazonium functions, respectively on silicon ${ }^{17}$ or glassy-carbon electrodes. ${ }^{18}$

As robust nano-scaled clusters displaying several discrete redox states, POMs are promising candidates for the implementation in n-type components of multi-level molecular memories, providing a parallel to complexes derived from ferrocene or porphyrins that have been assembled to get p-type components. ${ }^{19-22}$ In the latter case, the surface concentration has been shown to be a key parameter, strongly impacting the electron transfer rate and the charge retention time. ${ }^{19,20}$

For POM films to be included in hybrid silicon/ molecule electronics, several conditions have to be fulfilled: i) the film must be stable with time, temperature and under electrical stimulation, ii) its thickness must be controlled to a compact monolayer or submonolayer, as 
homogeneous multilayers are more difficult to obtain, iii) the electron transfer from the substrate to the POM must be as fast as possible and the charge dissipation rate as low as possible. This prompted us to inspect strategies to control the surface concentration of strongly bonded POMs on conducting surfaces. Since, the foreseen applications require the electrochemical activation of anchored POMs, the choice of tethering groups should be limited to those resistant to reduction, which excludes thiols that could desorb from the surface upon reduction. Functional surfaces with a good stability under electrochemical activation are then preferentially obtained from electrografting procedures. Among them, the most popular one is the reductive dediazonation of diazonium species. ${ }^{23-25}$

The reduction of diazonium salts fulfils the stability conditions since it provides covalently bonded layers, ${ }^{26,27}$ very stable with time $^{23}$ and temperature ${ }^{28}$ and potential resistant. ${ }^{29}$ Moreover, the grafted amount can be controlled from sub-monolayer to multilayer by varying the conditions for the electrografting procedure. ${ }^{30-33}$ Compton showed that electrografting in a $\mu \mathrm{M}$ diluted diazonium solution or upon decomposition of pre-adsorbed diazonium layer allows sub-monolayer surface coverage..$^{30,31}$ On the other hand, Pedersen and Daasbjerg showed that thick layers could be grown from surfaces by using an immobilized electroreducible group that can act as an electron relay, as the POMs could do. ${ }^{32,33}$

Moreover, together with the electrografting of diazonium functionalized POMs, the facile and strong adsorption of POMs onto electrodes ${ }^{11}$ and the formation of multilayers obtained by layer by layer attachment of POM anions and cations ${ }^{12}$ have to be considered. Since it has already been demonstrated that non covalently adsorbed layers may lose some material upon negative electrode polarization, ${ }^{12,34}$ the stability of the grafted layers should be considered. Here, we examine different experimental routes, reviewed in Scheme 1, to immobilize POMs onto glassy carbon $(\boldsymbol{G C})$ and gold $(\boldsymbol{A} \boldsymbol{u})$ substrates starting from a $\mathrm{NH}_{2}$ terminated Keggin-type POM hybrid, $\left(\mathrm{NBu}_{4}\right)_{4}\left[\mathrm{PW}_{11} \mathrm{O}_{39}\left(\mathrm{GeC}_{14} \mathrm{H}_{8} \mathrm{NH}_{2}\right)\right]$ designated as POM-NH $\mathbf{N H}_{2}$. Indeed, this 
platform allows standard bonding to a $\mathrm{COOH}$-terminated surface through peptidic coupling (route iii). It also opens the route to electrochemical or chemical grafting of surfaces through the generation of the corresponding diazonium POM hybrid, $\left(\mathrm{NBu}_{4}\right)_{3}\left[\mathrm{PW}_{11} \mathrm{O}_{39}\left(\mathrm{GeC}_{14} \mathrm{H}_{8} \mathrm{~N}_{2}\right)\right]$ designated as POM- $\mathbf{N}_{2}{ }^{+}$. We will discuss the influence of the experimental conditions on the electrochemical grafting of the latter diazonium POM hybrid on $\boldsymbol{G C}$ and $\boldsymbol{A} \boldsymbol{u}$ surfaces (route i). We will also examine the chemical grafting of $\mathbf{P O M}-\mathbf{N}_{\mathbf{2}}{ }^{+}$through its reduction by ascorbic acid or its thermal homolytic dediazonation (route ii). After a brief description of the grafting processes, spectroscopic surface analyses and electrochemical characterizations will provide insights into the stability of the grafted POM layers, the POM surface concentrations, and the electron transfer rates.

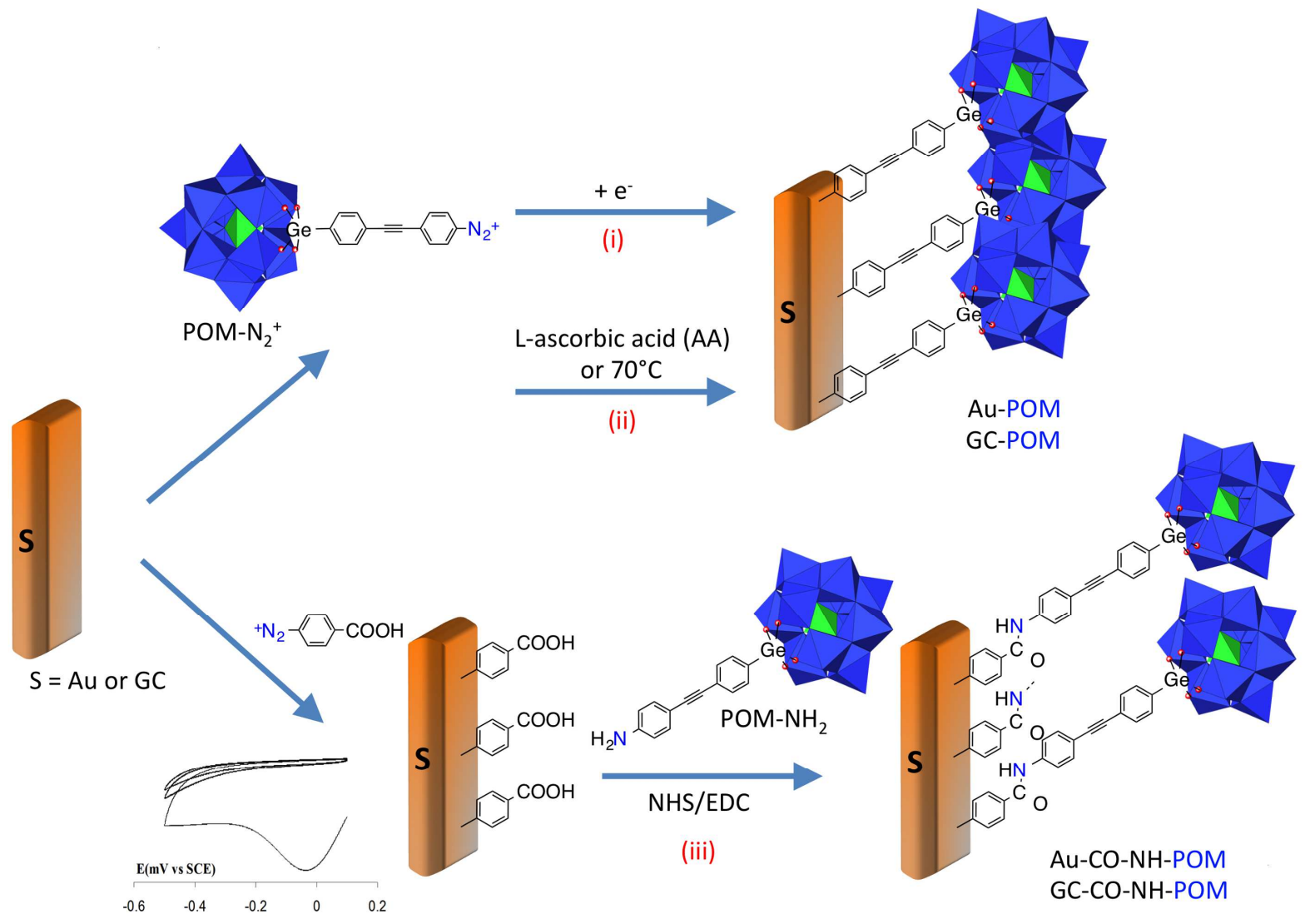

Scheme 1. Strategies for covalently modifying surfaces by $\mathbf{P O M}-\mathbf{N}_{\mathbf{2}}{ }^{+}$or $\mathbf{P O M}-\mathbf{N H}_{2}$ : i) electrografting, ii) chemical grafting, iii) peptidic coupling. 


\section{EXPERIMENTAL SECTION}

Substrates and POMs. Gold coated (100 nm, Aldrich) Si wafers were cut into $1.1 \times 1.1 \mathrm{~cm}^{2}$ plates. Before use, they were ultrasonically rinsed with acetone, water and ethanol and dried under argon. The plates were further treated in a UV-ozone cleaner (UVO cleaner, Jelight Company) just before use in order to remove the organic residues. The bare polished glassy carbon $(\boldsymbol{G C})$ plates $\left(1.1 \times 1.1 \mathrm{~cm}^{2}\right.$ from Sigradur HTW) were rinsed with ethanol, water and acetone, then dried under argon. $\boldsymbol{G C}$ electrodes ( 2 and $3 \mathrm{~mm}$ diameter) were polished on a polishing nap with $0.04 \mu \mathrm{m}$ alumina (Presi) and sonicated in acetone, water and ethanol.

The polyoxometalates $\left(\mathrm{NBu}_{4}\right)_{3}\left[\mathrm{PW}_{11} \mathrm{O}_{39}\left(\mathrm{GeC}_{14} \mathrm{H}_{8} \mathrm{~N}_{2}\right)\right](\mathrm{M}=3998 \mathrm{~g} / \mathrm{mol})\left(\mathbf{P O M}-\mathbf{N}_{2}{ }^{+}\right)$and $\left(\mathbf{N B u}_{4}\right)_{4}\left[\mathbf{P W}_{11} \mathbf{O}_{\mathbf{3 9}}\left(\mathbf{G e C}_{\mathbf{1 4}} \mathbf{H}_{\mathbf{8}} \mathbf{N H}_{2}\right)\right](\mathrm{M}=3986 \mathrm{~g} / \mathrm{mol}),\left(\mathbf{P O M}-\mathbf{N H}_{2},\right)$ were prepared following a previously described procedure detailed in the Supporting Information. ${ }^{18}$

Electrochemical Grafting of POM- ${ }_{2}^{+}$. The electrodes $(\boldsymbol{A u}$ and $\boldsymbol{G C})$ were modified by the hybrid POM using cyclic voltammetry in a solution of POM- $\mathbf{N}_{2}^{+}$(generally $1 \mathrm{mM}$ ) in $\mathrm{ACN}+$ $0.1 \mathrm{M} \mathrm{NBu}_{4} \mathrm{PF}_{6}$. Two different potential ranges were used by scanning between i) $\mathrm{R} 1:-0.1$ and -0.8 and, ii) R3: -0.1 and $-1.8 \mathrm{~V} / \mathrm{SCE}$; six cycles were repeated at a scan rate of $100 \mathrm{mV} / \mathrm{s}$. After electrografting, the electrodes, abbreviated by $\boldsymbol{A u}-\mathbf{P O M} \mathbf{M}_{\mathbf{R} 1}$ or R3 (respectively $\boldsymbol{G C}$ $\mathbf{P O M}_{\mathbf{R} 1}$ or $\mathbf{R 3}$ ), were thoroughly cleaned in $\mathrm{ACN}$ in an ultrasonic bath for $5 \mathrm{~min}$, then in acetone and stored under nitrogen. Multilayers of POMs on $\boldsymbol{G C}$ surfaces were obtained by cycling the electrode 20 times in the R3 range to give $\boldsymbol{G C}-\mathbf{P O M} \mathbf{R}_{\mathbf{R}}{ }^{\mathbf{2 0 c}}$.

Slightly different experimental conditions based on reported procedure were also used to obtain less densely grafted electrodes. ${ }^{30,31}$ Electrografting in the $\mathrm{R} 1$ range under identical conditions as those above except for a lower $\mathbf{P O M}-\mathbf{N}_{2}{ }^{+}$concentration $(100 \mu \mathrm{M})$ and a temperature of $0{ }^{\circ} \mathrm{C}$ instead of room temperature gave $\boldsymbol{A} \boldsymbol{u}$ or $\boldsymbol{G C}$ - $\mathbf{P O M} \mathbf{M}_{\text {low }}$ Moreover, preadsorption of a $100 \mu \mathrm{M} \mathbf{P O M}-\mathbf{N}_{2}{ }^{+}$solution in $\mathrm{ACN}$ at $0{ }^{\circ} \mathrm{C}$ was carried out for $300 \mathrm{~s}$ before electrografting in pure ACN to give $\boldsymbol{A} \boldsymbol{u}$ or $\boldsymbol{G C}-\mathbf{P O M}$ ads. 
The methods for grafting and characterization are detailed in the Supporting Information.

\section{RESULTS AND DISCUSSION}

\section{III.1. Grafting Modes of Functional POMs onto Gold and Glassy Carbon Surfaces.}

III.1.a. Electrografting from POM- $\mathrm{N}_{2}^{+}$. The cyclic voltammogram of a solution of $\mathrm{POMN}_{2}^{+}$ onto a $\boldsymbol{G C}$ electrode exhibits three cathodic peaks $(\mathrm{P} 1, \mathrm{P} 2, \mathrm{P} 3)$ at, respectively, Epc $=-0.49$, 1.02 and $-1.48 \mathrm{~V} / \mathrm{SCE}$ (Figure 1, A and B). P1 is a broad irreversible, monoelectronic peak, while $\mathrm{P} 2$ is reversible and $\mathrm{P} 3$ shows some reversibility. $\mathrm{P} 1$ is located in the typical potential region of diazonium salts and its height decreases on the second scan, as usually observed during the electrografting of diazonium salts. This indicates that i) $\mathbf{P O M}-\mathbf{N}_{\mathbf{2}}{ }^{+}$behaves as other diazonium salts ${ }^{23-25}$ and, ii) its electrochemical reduction leads to its grafting onto the surface; P2 and P3 correspond to the two successive one-electron reductions of the POM by comparison with the voltammogram of the same POM with a iodo termination instead of the tether $\left(\mathbf{N B u}_{4}\right)_{\mathbf{4}}\left[\mathbf{P W}_{\mathbf{1 1}} \mathbf{O}_{\mathbf{3 9}}\left(\mathbf{G e C}_{\mathbf{6}} \mathbf{H}_{\mathbf{4}} \mathbf{I}\right)\right]: \mathrm{E}^{\circ}=-0.99$ and $-1.46 \mathrm{~V} / \mathrm{SCE}^{18}$
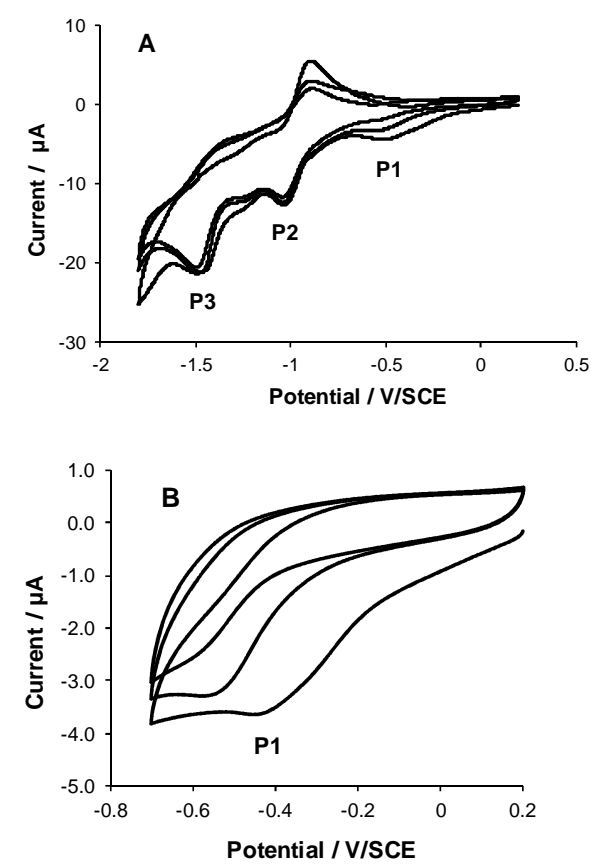

Figure 1. Cyclic voltammetry of $\mathbf{P O M}-\mathbf{N}_{2}{ }^{+}$in $\mathrm{ACN}+0.1 \mathrm{M} \mathrm{NBu}_{4} \mathrm{PF}_{6}: \boldsymbol{G C}$ electrode; $0.1 \mathrm{~V} \mathrm{~s}^{-1}$. 
On a $1 \mathrm{~cm}^{2} \boldsymbol{A u}$ plate (Figure SI1, Supporting Information), similar features are observed, which also lead to $\boldsymbol{A u}$ grafting.

The grafting of POM on a $\boldsymbol{G C}$ mm disk and an $\boldsymbol{A u} \mathrm{cm}$ plate by reduction of $\mathbf{P O M}-\mathbf{N}_{2}{ }^{+}$was conducted by cyclic voltammetry using two potential ranges: R1 between -0.1 and -0.8 V/SCE concerns only the diazonium wave P1, while R3 from -0.1 to $-1.8 \mathrm{~V} / \mathrm{SCE}$ encompasses the two waves of the reduction of the POM entity, P2 and P3. The grafted surfaces are abbreviated by $\boldsymbol{A u}$ - or $\boldsymbol{G C}$-POM $\mathbf{R 1 o r ~ R 3 . ~}$

Upon repetitive scanning in the $\mathrm{R} 3$ range, the intensities of $\mathrm{P} 2$ and $\mathrm{P} 3$ do not increase (Figures 1A and C). This result contrasts with those of Pedersen and Daasbjerg. ${ }^{32,33}$ They have shown that it is possible to obtain very thick films (up to $\sim \mu \mathrm{m}$ ) if the potential range of the scan encompasses both systems corresponding to the reduction of the diazonium function and the reversible system of the electroactive moiety in which a further electron can be stored (a nitrobenzene or anthraquinone moiety in their case). These particularly thick films result from electron transfers within the layer by electron exchange through the layer electron relays then to the solution diazonium species for further mediated and catalytic film growth. ${ }^{35}$ As stated above, P2 and P3 (Figure 1A) do not show an increased height of the wave upon repetitive scanning, indicating that the layer does not grow steadily; this is confirmed below by the thickness of the film that remains quite low (see later). As POMs can be reduced reversibly, electron transfers from the surface are possible in the R3 range. It is therefore likely that the layers remain quite thin because the aryl radical derived from $\mathbf{P O M}-\mathbf{N}_{\mathbf{2}}{ }^{+}$cannot attack an already grafted POM to form covalently bonded multilayers, which is not surprising considering that the POM is a bulky inorganic oxide.

To modulate the POM surface concentration, we have thus followed Compton's strategy developed during the electrografting of diazonium-terminated quinones. ${ }^{30,31}$ We have either (i) electrografted a $\boldsymbol{G C}$ electrode or an $\boldsymbol{A u}$ plate in a dilute $\mathbf{P O M}-\mathbf{N}_{\mathbf{2}}{ }^{+}$solution $(100 \mu \mathrm{M})$, or 
(ii) adsorbed a $100 \mu \mathrm{M}$ ACN solution of $\mathbf{P O M}-\mathbf{N}_{\mathbf{2}}{ }^{+}$onto a $\boldsymbol{G C}$ electrode or an $\boldsymbol{A u}$ plate for $300 \mathrm{~s}$, then electrografted the substrate in pure ACN (R1 range of potentials in both cases). These two procedures produce $\mathbf{A u}$ or $\mathbf{G C}-\mathbf{P O M} \mathbf{M}_{\mathbf{l o w}}$ and $-\mathbf{P O M}$ ads, respectively.

III.1.b. Chemical Grafting from POM- $\mathrm{N}_{2}^{+}$. Chemical grafting is illustrated by the reduction of $\mathbf{P O M}-\mathbf{N}_{2}{ }^{+}$by ascorbic acid $\left(\mathbf{A u}-\mathbf{P O M}_{\mathbf{A A}}\right)$ or by its thermal dediazonation at $70^{\circ} \mathrm{C}(\mathbf{A u}-$ $\left.\mathbf{P O M}_{\Delta}\right)$. The latter method is particularly simple, as it only necessitates depositing a thin layer of solution on the heated plate.

III.1.c. Chemical Grafting via Peptidic Coupling from POM-NH . Carboxylic terminated surfaces were prepared by electrochemical reduction of the 4-carboxybenzenediazonium salt (DCOOH) on an $\boldsymbol{A u}$ plate ${ }^{36}$ the thickness of the organic film $(\boldsymbol{A u}-\mathbf{C O O H})$ measured by ellipsometry, th $=0.9 \pm 0.3 \mathrm{~nm}$, is close to that of a monolayer. $\mathbf{P O M}-\mathbf{N H}_{2}$ was coupled to the latter modified surface through an amide bond by NHS-EDC activation to give $\boldsymbol{A u}$-CO-NHPOM (Scheme 1). ${ }^{16}$ The same method was used for the preparation of $\boldsymbol{G C}$-CO-NH-POM.

\section{III.2. Spectroscopic Characterization of Surface-Immobilized POM Layers.}

The thickness of the POM layers immobilized on large $\mathrm{cm}^{2} \boldsymbol{A} \boldsymbol{u}$ surfaces was obtained by ellipsometry and their chemical composition by XPS and IRRAS.

III.2.a. Ellipsometric Measurements. The values of the thickness of the layers, th, grafted on $\boldsymbol{A u}$ and measured by ellipsometry are represented in Figure 2B and thoroughly commented in the Supporting Information.

The values of th are generally lower than $6 \mathrm{~nm}$; they depend on the grafting mode employed and also on post-grafting treatments. Careful ultrasonication in ACN and acetone allows getting rid of adsorbed species, ${ }^{11}$ whilst cathodic polarization allows breaking electrostatic interactions in multilayers. ${ }^{12}$ It is noteworthy that electrochemical polarization of the films between -0.1 and $-1.8 \mathrm{~V} / \mathrm{SCE}$ results in a decrease of up to $2 \mathrm{~nm}$ of the layer thickness, as will 
be discussed later (compare full and open symbols in Figure 2B and see III.2.c). It shows the importance of the electrode polarization on the layer structuration. After polarization (see open symbols in Figure 2B), the highest thicknesses are obtained for electrografting and peptidic coupling (2-4 nm) and the lowest either by chemical grafting or by electrografting in dilute solutions (1-2 $\mathrm{nm})$.
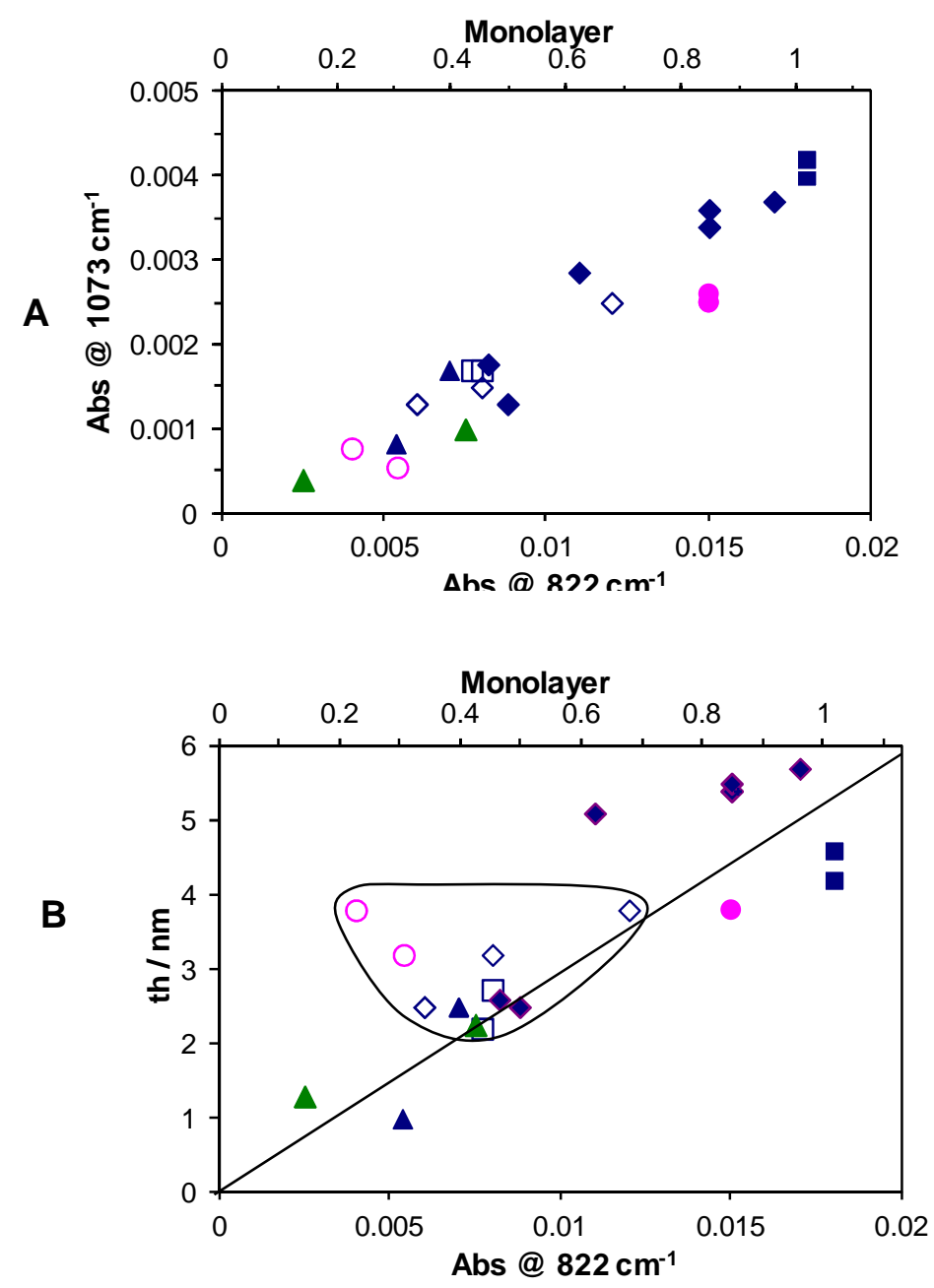

Figure 2. Comparison of IRRAS and ellipsometry characterizations of POM-immobilized surfaces obtained from electrografting: $\left(\boldsymbol{\square}\right.$, 口) $\boldsymbol{A u}-\mathbf{P O M}_{\mathbf{R} 1},(\bullet, \diamond) \boldsymbol{A u}-\mathbf{P O M}_{\mathrm{R} 3}$ and $\mathbf{\Delta} \boldsymbol{A u}-$

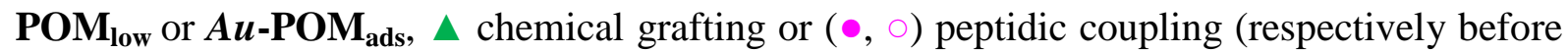
$(\bullet, \boldsymbol{\square}, \bullet)$ and after $(\diamond, \square, \circ)$ cathodic polarization of the grafted layer). A) Comparison of two IRRAS bands characteristic of the POM at 1073 and $822 \mathrm{~cm}^{-1}$. B) Comparison of IRRAS spectroscopy with ellipsometry. 
The experimentally estimated thicknesses can be compared with that of a monolayer. Since the length of the $-\mathrm{C}_{6} \mathrm{H}_{4}-\mathrm{C} \equiv \mathrm{C}-\mathrm{C}_{6} \mathrm{H}_{4}-$ tether is $\sim 1.1 \mathrm{~nm}$ and the POM has a $\sim 1.0 \mathrm{~nm}$ diameter, ${ }^{18}$ the theoretical thickness for a monolayer with $-\mathrm{C}_{6} \mathrm{H}_{4}-\mathrm{C} \equiv \mathrm{C}-\mathrm{C}_{6} \mathrm{H}_{4}-\mathrm{POM}$ moieties perpendicular to the surface is th $2.1 \mathrm{~nm}$. Jiang showed by DFT calculations that the phenyl groups attached to a gold surface through the reduction of diazonium salts are tilted by $38^{\circ}$ with respect to the surface normal. ${ }^{26}$ By analysis of the IR spectra of azobenzene grafted by reduction of its diazonium salt, McCreery found that the attached groups are tilted by $27<\Theta$ $<30^{\circ} .^{37}$ Therefore, the thickness of the monolayer should be within $1.8<$ th $<2.1 \mathrm{~nm}$. However, this estimation does not take into account the $\mathrm{NBu}_{4}{ }^{+}$counter ions. If the latter are located on top of the layer, 0.5 to $1.1 \mathrm{~nm}$ (depending on the geometry of the butyl chains) must be added to the length of the assembly, which leads for the global thickness to $2.3<$ th $<$ $3.2 \mathrm{~nm}$. In the case of the peptidic coupling, these values have to be increased by $0.7 \mathrm{~nm}$ to account for a monolayer of carboxybenzene anchor: $3.0<$ th $<3.9 \mathrm{~nm}$.

In conclusion, even though the thickness values exhibit some dispersion, films obtained through standard electrografting procedures are narrower than a bilayer and closer to a monolayer, while all other strategies yield unambiguously sub-monolayer coverage. A confrontation with specific spectroscopic signatures of the grafted layers is then required.

III.2.b. XPS and FT-IRRAS Characterizations. The survey XPS spectrum of an Au-POM 3 plate is shown in Figure SI2A (Supporting Information) presents the signals corresponding to $\mathrm{C} 1 \mathrm{~s}(\sim 285 \mathrm{eV}), \mathrm{O} 1 \mathrm{~s}(\sim 531 \mathrm{eV})$ and $\mathrm{W} 4 \mathrm{f}$. High resolution $\mathrm{W} 4 \mathrm{f}$ and $\mathrm{C} 1 \mathrm{~s}$ photoemission lines that are depicted in Figures SI2B and C, respectively, testify for the presence of a POM on the gold surface (see Supporting Information for a detailed investigation). An XPS analysis also confirms the presence of the POM in $\mathbf{A u}$-CO-NH-POM through the observation of the W4f

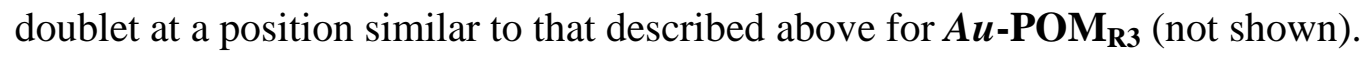


The presence of POM layers immobilized on $\boldsymbol{A} \boldsymbol{u}$ surfaces was also revealed by IR spectroscopy. Figure 3A illustrates the IRRAS spectra of electrochemically grafted $\boldsymbol{A u}$-POM surfaces. In the $1200-700 \mathrm{~cm}^{-1}$ region, the signature of the POM is confirmed by four significant peaks at $1073(v \mathrm{P}-\mathrm{O}), 970(v \mathrm{~W}=\mathrm{O}), 890$ and $822 \mathrm{~cm}^{-1}(v \mathrm{~W}-\mathrm{O}-\mathrm{W})^{38}$ that are similar to those of POM-NH $\mathbf{N H}_{2}$ (KBr pellet: 1073, 964, 887 and $807 \mathrm{~cm}^{-1}$ ); this indicates the integrity of the grafted POM. ${ }^{18}$ The characteristic IR signature for the stretching of the $\mathrm{N} \equiv \mathrm{N}^{+}$ bond $\left(2300-2130 \mathrm{~cm}^{-1}\right)$ in $\mathrm{POM}-\mathrm{N}_{2}{ }^{+}$was not detected. The surfaces obtained by chemical grafting present the same signatures and the thermal grafting is more efficient as it yields to the immobilization of four times more material than that proceeding by chemical reduction (Figure 3B). Thus, whatever the grafting method, the same unaltered POM species is present on the surface.

IRRAS was also used to monitor the formation of $\mathbf{A u}$-CO-NH-POM through the different assembling steps of the peptidic coupling between $\mathbf{A u}-\mathbf{C O O H}$ and $\mathbf{P O M}-\mathbf{N H}_{2}$ (Figure 3C). The modification of the gold electrode with $\mathrm{DCOOH}$ is confirmed by the presence of characteristic IR absorption bands: $\mathrm{vOH}$ (broad band) at $3300 \mathrm{~cm}^{-1}$ (not shown), $\mathrm{vC}=\mathrm{O}$ at $1725 \mathrm{~cm}^{-1}$, ring vibration at $1604 \mathrm{~cm}^{-1}$, and $\delta \mathrm{COO}^{-}$at $1450 \mathrm{~cm}^{-1}$ (spectrum a). After activation of the terminal acid groups by NHS/EDC, a new doublet appears at $1775,1741 \mathrm{~cm}^{-1}$, assigned to the $\mathrm{C}(=\mathrm{O})$-NHS-ester vibration (symmetric and asymmetric, respectively) associated with the disappearance of the $\mathrm{C}=\mathrm{O}$ vibration of the surface phenylcarboxylic groups (spectrum $\mathrm{b}$ ). Spectrum c corresponds to the surface obtained after reaction of POM-NH $\mathbf{N H}_{2}\left(24 \mathrm{~h}, 5 \times 10^{-4} \mathrm{M}\right.$ in $\mathrm{ACN}$ ). It indicates the successful covalent grafting of $\mathbf{P O M}-\mathbf{N H}_{2}$ through the formation of an amide bond characterized by the 1655 and $1545 \mathrm{~cm}^{-1}$ (respectively amide I and amide II) bands. The signature of the POM is also confirmed by the four significant peaks at 1073, 970, 890 and $822 \mathrm{~cm}^{-1}$. While decreasing, the band at $1741 \mathrm{~cm}^{-1}$ due to the carbonyl stretching vibrations of the activated acidic groups is still visible, indicating that most carboxylic groups 
of Au-COOH have not reacted. This is attributed to the steric hindrance of the bulky POM $(\sim 1$ $\mathrm{nm}),{ }^{18}$ which partially blocks the access to the carboxylic tether on the surface.
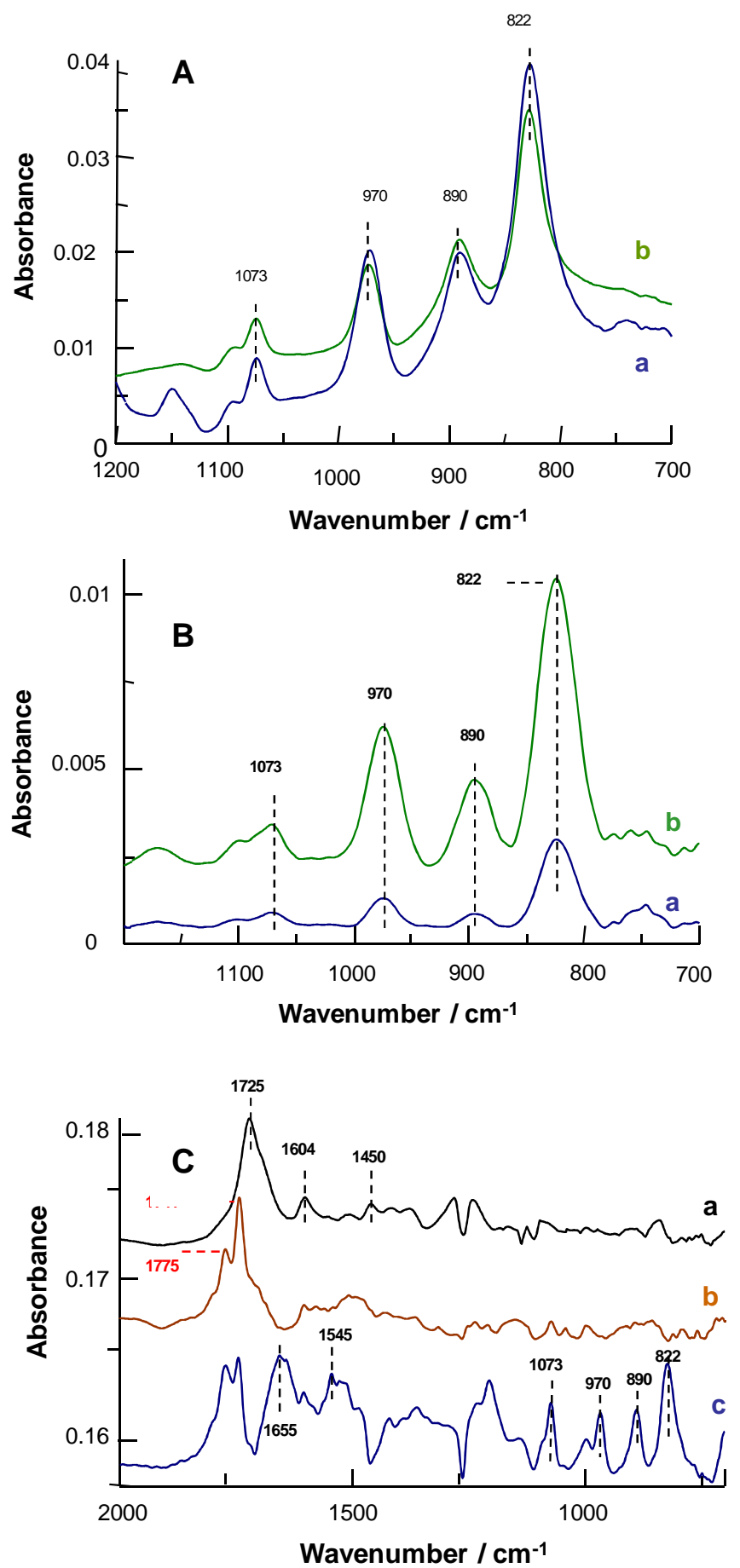

Figure 3. Comparison of the different grafting modes by FT IRRAS. A) (a) Au-POM $\mathbf{M}_{\mathbf{R} 1}$ and (b) Au-POM $\mathbf{R 3}$. B) chemical grafting: (a) reduction by ascorbic acid, (b) under heating at 70 ${ }^{\circ}$ C. C) peptidic coupling: (a) $\boldsymbol{A} \boldsymbol{u}-\mathbf{C O O H}$, (b) after NHS/EDC activation, (c) $\boldsymbol{A} \boldsymbol{u}$-CO-NHPOM. 


\section{III.2.c. Quantitative Characterization and Stability of POM Layers. Quantitative}

interpretation of the different immobilization processes was also provided from IRRAS analysis (Figure 2). Figure 2A compares the absorption peak heights of two characteristic bands (1073 and $822 \mathrm{~cm}^{-1}$ ) of the POM. For all the $\boldsymbol{A} \boldsymbol{u}$ surface-immobilized POM layers, there is a good correlation between the absorption of these two bands over almost one order of magnitude of absorbance, which points to the same POM structure.

A quantitative assessment of the surface coverage, $\Gamma$, is then obtained from the IRRAS absorbance of the most intense band for the POM $\left(822 \mathrm{~cm}^{-1}\right)$. To convert absorbances into surface coverages, as in Figure 2, a reference $\boldsymbol{A u}$ - $\mathbf{P O M} \mathbf{M}_{\mathbf{R} 3}$ sample was characterized by both IRRAS and electrochemistry that, as explained later in III.3.a., allows estimating the surface coverage (from the electrochemical charge of the $\mathbf{A u}-\mathbf{P O M} \mathbf{R}$ sample considered, $\Gamma=0.4 \times 10^{-}$ ${ }^{10} \mathrm{~mol} \mathrm{~cm}{ }^{-2}$ for a 0.008 absorbance at $822 \mathrm{~cm}^{-1}$ ). The absorbance, Abs, was then converted in monolayer (ML) units through (1), assuming the projection of the POM onto the electrode as a disk whose diameter is the distance between two POMS in a compact monolayer $(\mathrm{d}=1.44 \mathrm{~nm}) .{ }^{39}$ This

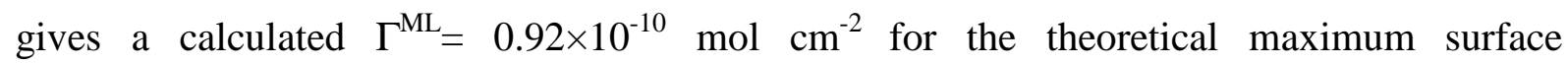
concentration for a compact monolayer.

$\Gamma / \Gamma^{\mathrm{ML}}($ in $\mathrm{ML}) \sim \operatorname{Abs}\left(@ 822 \mathrm{~cm}^{-1}\right) / 0.018$

Considering the top abscissa axes in Figures $2 \mathrm{~A}$ and B that convert the absorbances in $\mathrm{ML}$ using (1), all grafting methods lead to, at maximum, monolayer coverage. From (1), IRRAS can be used to monitor the evolution of the surface coverage upon grafting conditions and also upon post-grafting treatments.

For example, IRRAS shows that the layer is stable over time as there is no significant difference between the IRRAS spectra over a one month period (not shown).

IRRAS can also be used to monitor the effect of a cathodic polarization of the electrode on the layer composition (typically cycled 14 times from 0.2 to $-1.8 \mathrm{~V} / \mathrm{SCE}$ at a $0.5 \mathrm{~V} \mathrm{~s}^{-1}$ scan rate in $\left.\mathrm{ACN}+0.1 \mathrm{M} \mathrm{NBu}_{4} \mathrm{PF}_{6}\right)$. Cathodic polarization of $\boldsymbol{A u}-\mathbf{P O M}_{\mathrm{low}}$ and $\boldsymbol{A u}-\mathbf{P O M}_{\text {ads }}$ electrodes 
has no significant effect on their low POM surface coverage, confirming the absence of multilayer assembling. For more covered surfaces, such as $\boldsymbol{A u}-\mathbf{P O M} \mathbf{M}_{\mathbf{R} 3}$ or $\boldsymbol{A u}-\mathbf{P O M} \mathbf{R} \mathbf{1}$, the IRRAS spectra and the voltammograms for $\mathbf{A u}-\mathbf{P O M} \mathbf{R} 3$ recorded on the same plate before and after cycling are given respectively in Figures SI3A and B (Supporting Information). Both the IRRAS (band at $822 \mathrm{~cm}^{-1}$ ) and electrochemical (discussed later) signatures of the POM are still present but have decreased by $\sim 50 \%$ (from 0.7 to $0.4 \mathrm{ML}$ ) after the $14^{\text {th }}$ cycle. The main loss of POM is detected upon the first three cycles and no further change is observed in the IRRAS spectra after all subsequent cycles. This shows that, after three cycles, the POM film is electrochemically stable up to $-1.8 \mathrm{~V} / \mathrm{SCE}$ and confirms, as observed by ellipsometry in III.2.a., that under cathodic polarization, some POMs (likely retained by electrostatic interactions) $^{12}$ are removed from the $\boldsymbol{A} \boldsymbol{u}$ surface.

Comparison of IRRAS, surface coverage and ellipsometry is also insightful. Figure 2B compares the IRRAS absorbance at $822 \mathrm{~cm}^{-1}$, which specifically quantifies the POM from its chemical signature, with ellipsometry, which gives a physical estimate of the amount of material immobilized on the surface. For most samples, there is a rather fair correlation between the IRRAS absorbance at $822 \mathrm{~cm}^{-1}$ and the measured ellipsometric thickness.

The highest optical thicknesses observed suggest the presence of other immobilized species (solvent, electrolyte...), which are not revealed in the IRRAS characteristic bands of the POM. It means that both ellipsometry and IRRAS are compulsory to properly characterize the grafting and the grafted layers, ${ }^{40}$ especially if a monolayer or sub-monolayer coverage is sought.

For example, it is interesting to observe that, for the $\boldsymbol{A u}-\mathbf{P O M}_{\mathbf{R 3}}$ sample in Figure SI3A, a detectable amount of $\mathrm{PF}_{6}^{-}$(contribution at $850 \mathrm{~cm}^{-1}$ ) is entrapped within the POM layer. Such insertion that was observed in some grafted films, is currently under investigation. It explains the high optical thickness of that sample ( $\sim \mathrm{nm}$ for an estimated $0.7 \mathrm{ML}$ coverage). 
Moreover, the decrease of the POM content (to $0.4 \mathrm{ML}$ ) upon cycling is also associated to an increase of the $\mathrm{PF}_{6}^{-}$amount within the layer, as a result of the layer restructuration by cleavage of POMs attached by electrostatic interactions and insertion of anions.

The case of $\boldsymbol{A u}$-CO-NH-POM is also significant (circles in Figure 2B). IRRAS also shows that the amount of immobilized POM greatly decreases upon electrochemical polarization of the surface from monolayer coverage before activation to $0.3 \mathrm{ML}$ coverage after activation, while no significant change of the optical thickness is detected. This is in line with the electrochemical investigation of $\boldsymbol{G C}$-CO-NH-POM in III.3.a., which indicates the same effect and gives the same surface coverage. It confirms that upon peptidic coupling, as well as upon electrografting, the surface presents both covalently bound POMs (20-30\%) and POMs attached by electrostatic interactions $(70-80 \%)$. The latter can be removed by cathodic polarization and probably replaced by electrolyte ions to account for the constant thickness.

Altogether, these experiments indicate that it is possible to remove non-covalently bonded POMs (attached by electrostatic interactions) from the $\boldsymbol{A} \boldsymbol{u}$ surface by three electrochemical cycles to $-1.8 \mathrm{~V} / \mathrm{SCE}$, but that some electrolyte can remain entrapped in the film. Together with the electrochemically stability achieved after a 3-cycle polarization, this particularly highlights the strength of the diazonium procedure for the immobilization of reducible functional groups on surfaces. Indeed, a thiol terminated POM derivative would have been impossible to characterize under electrochemical activation and therefore likely inoperative for the preparation of n-type molecular memories.

\section{III.3. Electrochemical Characterization of Immobilized POM Surfaces.}

We have shown that different strategies can be used to immobilize POMs onto electrode surfaces. However, the layer is sensitive to cathodic polarization, for example during its electrochemical characterization, which leads to subsequent layer reorganization and, among 
others, to the loss of POMs attached by electrostatic interactions. This suggests that proper electrochemical characterizations of the grafted layers must be performed when all noncovalently immobilized POMs have been desorbed.

The redox behavior of the grafted POM surfaces was evaluated by voltammetric techniques, here namely cyclic voltammetry (CV) and square wave voltammetry (SWV), a differential technique described in the Supporting Information and more adapted to the detection of diluted electroactive species. ${ }^{41}$ This study allowed both characterizing the surface coverage of POM layers immobilized onto electrode surfaces and accessing $\mathrm{k}_{\mathrm{app}}$, the apparent rate constant for the transfer of charge to such immobilized POMs.

III.3.a. General Behavior of POM Layer and Surface Coverage Estimate. As reported previously for a $\boldsymbol{G C}$ electrode covered with a monolayer of POM, two reversible redox waves at $\mathrm{E}^{\circ}=-1.01$ and $-1.50 \mathrm{~V} / \mathrm{SCE}$ are observed by $\mathrm{CV} .{ }^{18} \mathrm{~A}$ similar electrochemical behaviour is observed at cm large $\boldsymbol{A} \boldsymbol{u}$ electrodes, as illustrated in Figure SI3B for the reference $\boldsymbol{A u}$-POM $\mathbf{P} \mathbf{3}$ used, in III.2.c, to convert IRRAS Abs into surface coverage (1). The first electrochemical polarization of the grafted layer (first cathodic peak, P2) corresponds to a slightly higher charge injection than on the reversed anodic peak. This effect disappears when the scan rate is increased $\left(\mathrm{v}>0.5 \mathrm{~V} \mathrm{~s}^{-1}\right)$ or after several $\mathrm{CVs}\left(3^{\text {rd }} \mathrm{CV}\right.$ identical to the $14^{\text {th }} \mathrm{CV}$, as presented in Figure SI3B B). It confirms the spectroscopic observation of some POM removal from the layer upon reductive polarization of the electrode. From the integration of the first cathodic peak, such loss of POM is evaluated to $\sim 43 \%$, which is in agreement with the $\sim 50 \%$ decrease of the $822 \mathrm{~cm}^{-1}$ IRRAS peak (Figure SI3A). The POM surface concentration, $\Gamma$, is estimated from the integration of the first system at $-1.1 \mathrm{~V} / \mathrm{SCE}$ after the $3^{\text {rd }}$ cycle. For the $\boldsymbol{A u}-\mathbf{P O M} \mathbf{M}_{\mathbf{R} 3}$ surface in Figure SI3B, it is $\Gamma=0.4 \times 10^{-10} \mathrm{~mol} \mathrm{~cm}^{-2}\left(\sim 0.4 \Gamma^{\mathrm{ML}}\right)$.

As a next step, the impact of the modulation of POM surface coverage on the POM layer electrochemical characteristics is studied. To decrease the ohmic drop and capacitive current 
contributions and get more precise surface concentration estimates, grafted $\boldsymbol{G C}$ mm electrodes were preferred to $\boldsymbol{A u} \mathrm{cm}$ plates whose surface area is less precisely known. The resulting change in topology was estimated as negligible when taking into account the dispersion of the results. The immobilization of a monolayer of POM was demonstrated elsewhere. ${ }^{18}$ As suggested by the IRRAS characterization of $\boldsymbol{A u}$-POM surfaces (Figure 2), the electrografting may also generate sub-monolayer coverage. This is reproduced on $\boldsymbol{G C}$ electrodes for $\boldsymbol{G C}$ $\mathbf{P O M}_{\mathbf{R} 1}$ after electrochemical polarization (Figures 4A and B). The surface concentration of

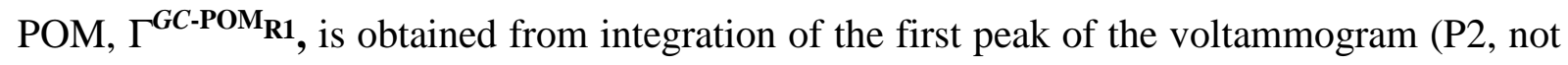
shown) or equivalently from the slope of the linear variation of the peak intensity with $\mathrm{v}$ observed on P2 in Figure 4A. It is $0.5 \times 10^{-10} \mathrm{~mol} \mathrm{~cm}^{-2}\left(\sim 0.6 \Gamma^{\mathrm{ML}}\right)$ for the example shown in Figures 4A and B. More generally, it ranges from 0.45 to $1.0 \times 10^{-10} \mathrm{~mol} \mathrm{~cm}^{-2}(\sim 0.5$ to $\sim 1.1$ $\Gamma^{\mathrm{ML}}$ ) from different samples. Therefore, $\Gamma^{G C-\mathbf{P O M}_{\mathbf{R} 1}}$ and $\Gamma^{G C-\mathbf{P O M}_{\mathbf{R} 3}}$ are in the range of $\Gamma^{\mathrm{ML}}$, and the electrografting leads to, at maximum, monolayer electrode coverage.

As suggested by the spectroscopic characterization on $\boldsymbol{A u}$ (Figure 2), $\boldsymbol{G C}$-POM $\mathbf{M M}_{\mathrm{low}}$ and $\boldsymbol{G C}$ $\mathbf{P O M}_{\text {ads }}$ electrodes lead to lower surface coverages. The CV (Figure 4E left and Figure SI4 in Supporting Information for $\boldsymbol{G C}$-POM $\mathbf{P a d s}_{\text {s }}$ electrode) is qualitatively comparable to that obtained for other grafted monolayers, but the amount of immobilized POM is $3 \times 10^{-11}$ and $10^{-}$

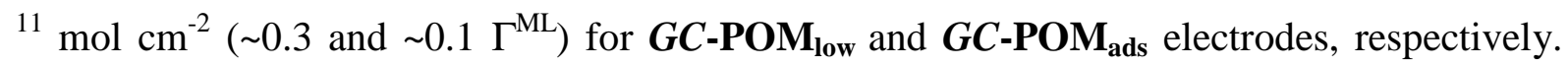
Working under such conditions allows a better control toward sub-monolayer surface coverage. As stated in the introduction, this is a promising strategy since lower surface coverage of molecular memories is a possible way to obtain devices with higher charge transfer rates. $^{20,21}$

GC-CO-NH-POM surfaces obtained by peptidic coupling were characterized by SWV since the grafted layer is so thin that the capacitive current observed by CV screens the 
electrochemical signature of the POM. Figure SI5A (Supporting Information) shows an example of a SWV response of $\boldsymbol{G C}$-CO-NH-POM recorded between -0.6 and $-1.6 \mathrm{~V} / \mathrm{SCE}$ at different frequencies, $f$. As during $\mathrm{CV}$ characterization of electrografted surfaces, some electroactive material has been lost upon the first scanning. The $\boldsymbol{G C}$-CO-NH-POM electrode presents a single and $\sim$ twice broader cathodic reduction peak at the same potential as $\boldsymbol{G C}$ $\mathbf{P O M}_{\mathbf{R} 1}$, corresponding to the first redox system of the POM (peak P2).

This broad peak suggests that the POM coupled to the organic layer by a peptidic link presents a distribution of different chemical environments or orientations, while the electrografting generates a more homogeneous functional surface. The estimate of an overall averaged surface coverage is obtained from the variation of the integrated SWV signal with the SWV frequency, $f$ (Figure SI5B) for three different surfaces coupled with POMs through a peptidic bond. An average surface concentration, $\Gamma^{G C \text {-CO-NH-POM }}$, and an apparent charge transfer rate constant, $\mathrm{k}_{\mathrm{app}}$, can be deduced from fitting the experimentally measured charge obtained from integration of the voltammograms with their predicted evolution with $f^{41}$

Depending on the sample, the coverage of the surface by POM from peptidic coupling can vary by a factor of two but is always much lower than a few tenths of a monolayer.

The different grafting routes investigated allow the tuning of the POM surface concentration from sub-monolayer to monolayer, which gives for grafted $\boldsymbol{G C}$ surfaces:

$$
\begin{gathered}
0.1 \Gamma^{\mathrm{ML}} \sim \Gamma^{G C \text {-CO-NH-POM }} \sim \Gamma^{G C \text {-POMads }}<\Gamma^{G C \text {-POMlow }}<0.3 \Gamma^{\mathrm{ML}} \\
0.5 \Gamma^{\mathrm{ML}}<\Gamma^{G C \text {-POM }} \text { R1 } \& 3_{3}<\sim \Gamma^{\mathrm{ML}}
\end{gathered}
$$

with $\Gamma^{\mathrm{ML}}=0.92 \times 10^{-10} \mathrm{~mol} \mathrm{~cm}{ }^{-2}$ for the theoretical surface coverage of a compact monolayer.

If the surface coverage by a monolayer or a sub-monolayer of POMs can be obtained by electrografting procedures or chemical coupling, it is also possible to obtain multilayers of POMs on surfaces by performing a higher number of cycles up to $-1.8 \mathrm{~V} / \mathrm{ECS}$ (here 20 cycles, 
GC-POM ${ }_{\mathbf{R} 3}{ }^{20 c}$ ). A typical cyclic voltammogram obtained for such a grafted electrode is given in Figure 4E (right). It presents two reduction systems assigned to the two successive reversible electron transfers at potentials close to those of the species in solution, $\mathrm{P} 2$ and P3 or to monolayer covered electrodes $(-1.01$ and $-1.50 \mathrm{~V} / \mathrm{SCE})$. As for the other grafted electrodes with lower surface coverages, the first wave presents a shoulder on the cathodic scan that disappears either when increasing the scan rate above $0.5 \mathrm{~V} \mathrm{~s}^{-1}$ or after several reductive electrochemical polarizations. The integration of the four peaks observed in Figure 4E (right) at $0.1 \mathrm{~V} \mathrm{~s}^{-1}$ shows that the amount of charge transferred during the first reduction, $3.3 \mu \mathrm{C}$, is twice higher than that detected on each individual other step, $1.6 \mu \mathrm{C}$. The excess of charge transferred on the shoulder of the first reductive peak $(3.3-1.6=1.7 \mu \mathrm{C})$ is likely associated to an irreversible transformation of deposited species along the scanned potential range. As for that detected at lower surface coverages, it is attributed to the reductive desorption of POMs attached by electrostatic interactions.

The $1.6 \mu \mathrm{C}$ charge exchanged on the other steps is relative to the reversible transfer of $1 \mathrm{e}^{-}$to the immobilized POMs with a POM surface coverage of $\Gamma^{\mathbf{G C}^{-} \cdot \mathbf{P O M}_{\mathbf{R 3}}{ }^{\mathbf{2 0 c}}}=5 \times 10^{-10} \mathrm{~mol} \mathrm{~cm}^{-2}(5$

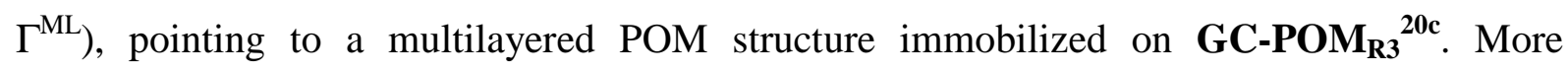
thorough analysis on the formation of multilayers is under current investigation and likely results from the electrostatic adsorption of further POM layers atop a covalently grafted monolayer.

III.3.b. Charge Transfer Kinetics. Kinetic analysis of the charge transfer properties of the surface-immobilized POM layers was obtained from the observation of the voltammetric response at different scan rates, $\mathbf{v}$, or frequencies, $f$. Large area $\boldsymbol{A} \boldsymbol{u}$ surfaces are not appropriate for such investigation as at high frequency activation, it is difficult to extract the POM signal from the noise level and to compensate efficiently the ohmic drop contribution. 
As in the latter study of the modulation of POM surface coverage, the following kinetic discussion then rather focuses on the behavior of millimeter $\boldsymbol{G C}$ grafted surfaces.

To perform kinetic analysis, stable systems, which are not prone to desorption of POMs, have to be addressed. This condition is fulfilled after several potential polarizations. The variation of the peak potentials and peak currents with the scan rate of reproducible cyclic voltammograms for scan rates ranging from 0.1 to $500 \mathrm{~V} \mathrm{~s}^{-1}$ are presented for POM surface concentrations of $5 \times 10^{-11} \mathrm{~mol} \mathrm{~cm}^{-2}\left(\sim 0.5 \Gamma^{\mathrm{ML}}, \boldsymbol{G C}\right.$-POM $\mathbf{R} 1$ in Figures $4 \mathrm{~A}$ and B) and $10^{-11}$ $\left(\sim 0.1 \Gamma^{\mathrm{ML}}, \boldsymbol{G C}-\mathbf{P O M}_{\mathrm{ads}}\right.$ in Figure 4C).

The $\boldsymbol{G C}$-POM $\mathbf{R} \mathbf{1}$ electrografted surface behaves similarly to the monolayer covered surface previously described : the cathodic and anodic peak intensities for P2 increase linearly with v for $0.5<\mathrm{v}<30 \mathrm{~V} \mathrm{~s}^{-1}$, then tend toward a dependency with $\mathrm{v}^{1 / 2}$ at higher $\mathrm{v}$ (Figure 4A). ${ }^{18}$ This indicates that at slow $\mathrm{v}$, the reduction process is controlled by the electron transfer between the surface and the anchored POM, while at higher v, diffusion limitations are encountered. These diffusion limitations were attributed to hopping processes associated to the transport of charge in the layer upon electron transfer from the electrode.

The cathodic and anodic peak potentials of the P2 system are constant for $\mathrm{v}<10 \mathrm{~V} \mathrm{~s}^{-1}$, indicating a fast electron transfer (Figure 4B). At low scan rates, the electron transfer is fast, however the cathodic and anodic peaks of the P2 system are not located at the same potentials and are separated by 25 to $35 \mathrm{mV}$. It attests the contribution of the electrostatic work associated to the transfer of an electron to the negatively-charged POM. This peak potential separation is twice higher, $80 \mathrm{mV}$, for the second electron transfer, $\mathrm{P} 3$, in agreement with the even higher electrostatic work needed for further electron injection in the already reduced POM structure. For v $>10 \mathrm{~V} \mathrm{~s}^{-1}$, the peak-to-peak separation increases, showing some kinetic limitation by the charge transfer processes (Figure 4B). The cathodic and anodic peak 
potentials deviations from constancy occur at the same scan rate, indicating that the ratelimiting process on both anodic and cathodic scans is the same.

The experimental variations of the cathodic and anodic potentials with $\mathrm{v}$ for the P2 system have been compared to theoretical predictions for reversible electron transfer to a surfaceconfined species. A detailed description of the theoretical interpretation of these peak potential variations is given elsewhere. ${ }^{18}$ Briefly, in Figures $4 \mathrm{~B}$ and $\mathrm{C}$, the experimental data are compared with the trumpet-like theoretical variations for slow electron transfer limitation. The deviations from the theoretical lines observed at higher scan rate in Figure 4B cannot be accounted for ohmic drop contribution. Resitance effects generally exalt the peak separation. The smaller peak separation is rather indicative of the intervention of diffusion limitation (hopping with apparent diffusion coefficient $D_{a p}=8 \times 10^{-11} \mathrm{~cm}^{2} \mathrm{~s}^{-1}$ ), as also suggested by the peak current variations in Figure 4A. However, an apparent limiting charge transfer rate, $\mathrm{k}_{\mathrm{app}}$, can be obtained from the fitting at lower $\mathrm{v}$. The ensuing apparent charge transfer rate constant ranges between $\mathrm{k}_{\mathrm{app}}=700$ and $1100 \mathrm{~s}^{-1}$ for different $\boldsymbol{G C}$-POM electrodes of $0.5 \Gamma^{\mathrm{ML}}<\Gamma^{G C \text { - }}$ POMR1\&3 $<\Gamma_{\mathrm{ML}}$. For the most diluted POM surface, $\boldsymbol{G C}$-POM $\mathbf{P d s}_{\text {of }} \Gamma^{\boldsymbol{G C} \text {-POMads }}=0.1 \Gamma^{\mathrm{ML}}$, the peak potential variations with the scan rate (Figure 4C) are similar to those observed for $\boldsymbol{G C}$ $\mathbf{P O M}_{\mathbf{R} 1}$ and a rate constant $\mathrm{k}_{\mathrm{app}}=600 \mathrm{~s}^{-1}$ is obtained. The peak separation (electrostatic work) associated to each electron transfer is also of the same order (respectively $\Delta \mathrm{E}_{\mathrm{p}}=23$ and 80 $\mathrm{mV})$.

For the latter surfaces electrografted with sub- to monolayer of POM, the measured $k_{\text {app }}$ values do not significantly depend on the POM surface coverage, in contrast with porphyrins (for example for a porphyrin bonded to $\mathrm{Si}(100)$, when $\Gamma$ increases from $10^{-12}$ to $6 \times 10^{-11} \mathrm{~mol}$ $\mathrm{cm}^{-2}, \mathrm{k}_{0}$ decreases from $>5 \times 10^{4}$ to $\left.5 \times 10^{3} \mathrm{~s}^{-1}\right){ }^{20,21}$ This indicates that the kinetically limiting (hopping) process concerns charge transfer from the electrode to the POM and is not related to lateral diffusion or inter-neighbour interactions. This is confirmed by the very similar 
values of the peak potential separation within the surface concentration range spanned. It is indicative of an electrostatic contribution, likely due to charge transfer to the negatively charged POM structure, which shows similar charge screening by the counter-ion cloud in dense or dilute assemblies.

For electrodes covered with multilayers, the Ep-v analysis (as in Figure 4D for a sample with $\Gamma=4.2 \Gamma_{\mathrm{ML}}$ ), shows that kinetic limitation appears at a $\sim 7$ times lower scan rate than in Figures 4A-C. The limiting process associated to the charge transfer process is then slower and $\mathrm{k}_{\mathrm{app}}=120 \mathrm{~s}^{-1}$. The decrease of the charge transfer process kinetic with the surface coverage is clearly evidenced for multilayer coverage. This is in agreement with observations on porphyrin systems for which the higher the surface coverage, the slower the charge transfer process. In this regime of compact charge stacking, inter-neighbour interaction or transport is likely operative.

For $\boldsymbol{G C}$-CO-NH-POM, an apparent charge transfer characterization is obtained by SWV from the fit of the experimental variation of the integrated SWV signal, with the SWV frequency, $f$ to the theoretical peak shaped evolution (Figure SI5B). For the three grafted electrodes of $\Gamma^{G C-C O-N H-P O M}=1.3,2$ and $2.5 \times 10^{-11} \mathrm{~mol} \mathrm{~cm}^{-2}, \mathrm{k}_{\text {app }}=3,0.3$ and $25 \mathrm{~s}^{-1}$ are obtained, respectively. The charge transfer rate constant varies along two orders of magnitude. However, it is always two orders of magnitude lower than for directly electrografted layers. This probably results from the length and the not fully conjugated nature of the organic linker coupling the POM moiety to the electrode surface. Such length is related to the thickness of the electrografted $-\mathrm{C}_{6} \mathrm{H}_{4} \mathrm{COOH}$ seeding layer. Even though the latter cannot be directly accessed for the $\boldsymbol{G C}$ used for the electrochemical characterization, ellipsometry shows on a cm large $\boldsymbol{A} \boldsymbol{u}$ surface that such layer can vary from monolayer $(0.6 \mathrm{~nm})$ to multilayer $(\sim 2 \mathrm{~nm})$, explaining the differences in $\mathrm{k}_{\mathrm{app}}$. 

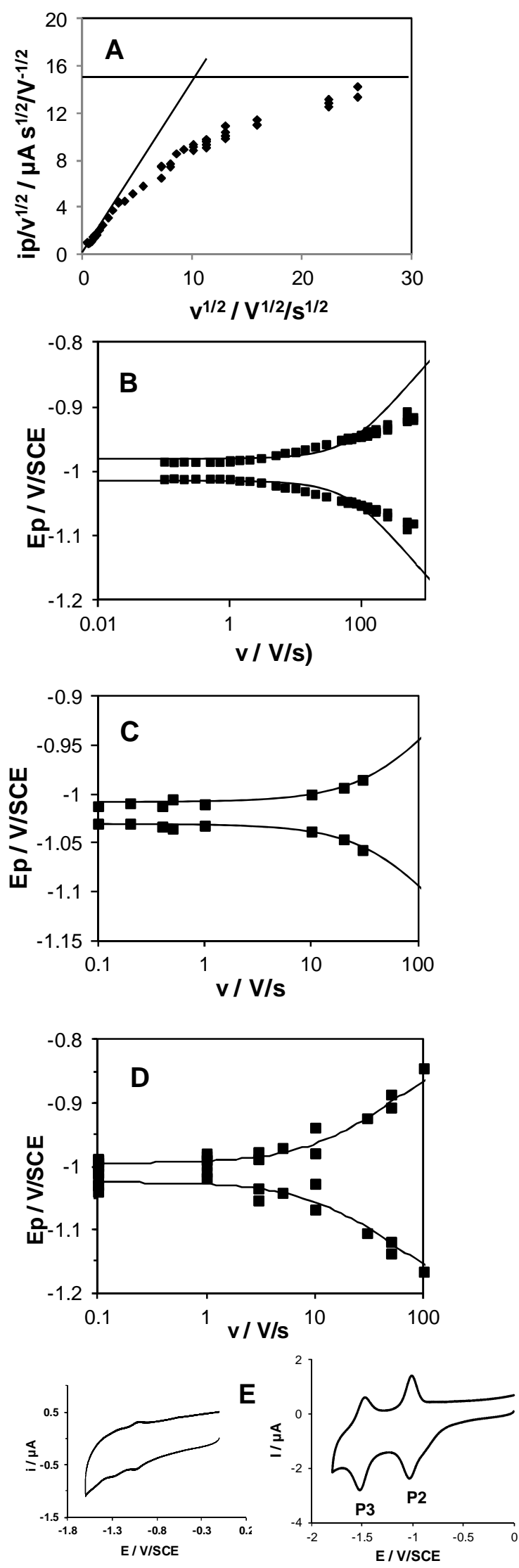

Figure 4. Cyclic voltammetry of $\boldsymbol{G} \boldsymbol{C}$-POM electrodes in $\mathrm{ACN}+0.1 \mathrm{M} \mathrm{NBu}_{4} \mathrm{PF}_{6}$. A, B) $\boldsymbol{G} \boldsymbol{C}$ -

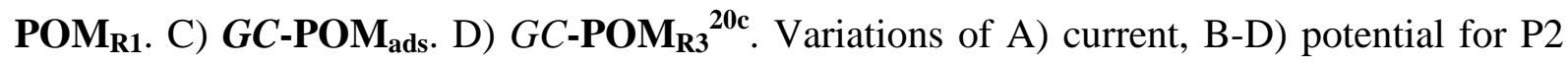
with $v$. E) $v=0.1 \mathrm{~V} \mathrm{~s}^{-1}$, left: $\boldsymbol{G C}$-POM $\mathbf{P O d s}_{\mathbf{a d s}}(0.1 \mathrm{ML})$; right: $G C-\mathbf{P O M}_{\mathbf{R 3}}{ }^{20 c}$ (5 ML). SCE reference. $2 \mathrm{~mm}$ diameter electrode. 


\section{CONCLUSION}

Diverse $\mathrm{cm}^{2} \boldsymbol{A} \boldsymbol{u}$ and $\mathrm{mm}^{2} \boldsymbol{G C}$ surface-immobilized POM layers were prepared, as the first step toward the formation of hybrid (silicon-molecular) memories.

The modified surfaces have been thoroughly investigated to provide a complete characterization; in addition to demonstrating the robust attachment of the POMs, the surface concentration, the thickness of the layer and the rate constant for electron transfer from the surface to the POM have been measured. It is particularly underlined that the use of complementary techniques is mandatory to improve the description and thus to control the composition of the modified electrodes.

Depending on the experimental conditions, the grafting is controlled from 0.1 to 5 monolayers. The electrografting of POM- $\mathbf{N}_{2}{ }^{+}$is more complicated than that of purely organic diazonium salts as besides the covalent grafting on the electrode, additional POMs attached by electrostatic interactions are present in the film. This is also true for peptidic coupling on a seed layer. Cathodic polarization of the grafted surface results in the cleavage of POMs attached by electrostatic interactions and structuration of the grafted layer, as also evidenced from ellipsometry and IRRAS. The grafting on $\boldsymbol{G C}$ electrodes is more stable toward electrochemical polarization than on $\boldsymbol{A u}$ ones. Cathodic polarization provides a unique tool to get rid of such ionic bonded POMs and stable layers of covalently anchored POMs are obtained after several scans, which allows quantitative electrochemical characterization of charge storage and kinetics of charge injection rate.

From 0.1 to 1 monolayer, the kinetically limiting process is $600-1100 \mathrm{~s}^{-1}$, with no evident surface concentration dependence, in distinct contrast with porphyrin-based materials. A decrease of the limiting process rate is observed when increasing the surface coverage to multilayers. This suggests that cooperative effects or inter-neighbour charge transfer are 
operative in multilayers, while for sub- to monolayers, charge transfer from the surface to the POM moiety is the limiting process.

We are now able to control the formation of monolayers or sub-monolayers of covalently grafted POMs on $\boldsymbol{G C}$ and $\boldsymbol{A u}$ that are stable with time or potential, which is a requisite toward the design of molecular memories. This paper opens the way to further investigations aiming at a better understanding of the role of the POM counter cations on the kinetics of the electron transfer. Attachment of similar diazonium POMs onto silicon in dry state devices is also under work.

\section{ASSOCIATED CONTENT}

\section{Supporting Information}

Chemicals, experimental details for chemical grafting and peptidic coupling of $\mathbf{P O M - \mathbf { N H } _ { 2 }}$ with a carboxylic derivatized surface, characterization methods, ellipsometric measurements, electrografting onto $\mathrm{Au}$, ellipsometric measurements, XPS for $\boldsymbol{A u}-\mathbf{P O M} \mathbf{M}_{\mathbf{R} 3}$, stability to cathodic polarization, cyclic voltammetry of $G C$-POM ${ }_{\text {ads }}$, SWV for $G C$-CO-NH-POM.

\section{Acknowledgements}

The authors gratefully acknowledge support from the CNRS, ESPCI, the Langlois Foundation and UPMC for a PhD fellowship to $\mathrm{CR}$ and the MiChem Labex for post-doctoral fellowship to SGD. Rabah Benbalagh is thanked for his contribution to XPS. 


\section{Table of Contents}

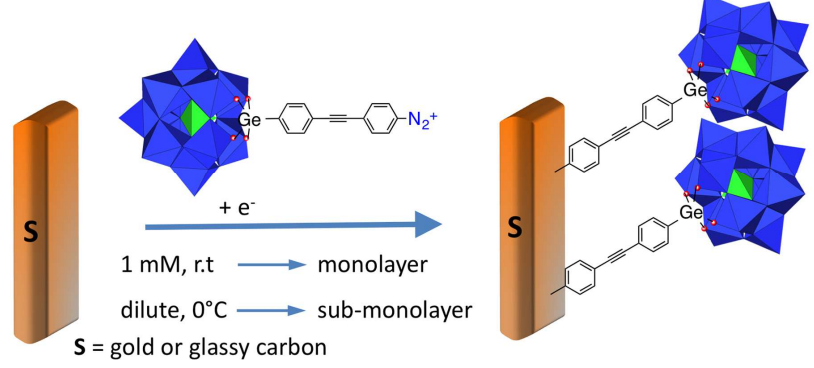


${ }^{1}$ Zhang, Z. Y.; Lin, Q. P.; Zheng, S. T.; Bu X. H.; Feng, P. Y. A novel sandwich-type polyoxometalate compound with visible-light photocatalytic H-2 evolution activity. Chem. Commun. 2011, 47, 3918-3920.

${ }^{2}$ Matt, B.; Fize, J.; Moussa, J.; Amouri; H.; Pereira, A.; Artero, V.; Izzet, G.; Proust, A. Charge photo-accumulation and photocatalytic hydrogen evolution under visible light at an iridium(III)-photosensitized polyoxotungstate. Energy and Environmental Science 2013, 6, 1504-1508.

${ }^{3}$ Chakraborty, S.; Keightley, A.; Dusevich, V.; Wang, Y.; Peng, Z.H. Synthesis and Optical Properties of a Rod-Coil Diblock Copolymer with Polyoxometalate Clusters Covalently Attached to the Coil Block. Chem Mater 2010, 22, 3995-4006.

${ }^{4}$ Luo, X. Z.; Li, F. Y.; Xu, B. B.; Sun, Z. X.; Xu, L. Enhanced photovoltaic response of the first polyoxometalate-modified zinc oxide photoanode for solar cell application. J. Mater. Chem. 2012, 22, 15050-15055.

${ }^{5}$ He, T.; He, J. L.; Lu, M.; Chen, B.; Pang, H.; Reus, W. F.; Nolte, W. M.; Nackashi, D. P.; Franzon, P. D; Tour, J. M. Controlled modulation of conductance in silicon devices by molecular monolayers. J. Am. Chem. Soc. 2006, 128, 14537-14541.

${ }^{6}$ Douvas, A. M.; Makarona, E.; Glezos, N.; Argitis, P.; Mielczarski, J. A.; Mielczarski, E. Polyoxometalate-based layered structures for charge transport control in molecular devices. ACS Nano 2008, 2, 733-742.

${ }^{7}$ Lu, M.; Nolte, W. A.; He, T.; Corley, D. A.; Tour, J. M. Direct Covalent Grafting of Polyoxometalates onto Si Surfaces. Chem. Mater. 2009, 21, 442-446.

${ }^{8}$ Wang; H.; Hamanaka, S.; Nishimoto, Y.; Irle, S; Yokoyama, T.; Yoshikawa, H.; Awaga, K. In Operand X-ray Absorption Fine Structure Studies of Polyoxometalate Molecular Cluster Batteries: Polyoxometalates as Electron Sponges. J. Am. Chem. Soc. 2012, 134, 4918-4924.

9 Cuentas-Gallegos, A. K.; Lira-Cantu, M.; Casan-Pastor, N.; Gomez-Romero, P.; Nanocomposite hybrid molecular materials for application in solid-state electrochemical supercapacitors. Adv Funct. Mater. 2005, 15, 1125-1133.

${ }^{10}$ Liu, S. Q.; Tang, Z. Y. Polyoxometalate-based functional nanostructured films: Current progress and future prospects. Nano Today 2010, 5, 267-281. 
$\overline{{ }^{11} \text { Keita, B.; Nadjo, L.; Belanger, D.; Wilde, C. P.; Hilaire, M. Electrochemical quartz-crystal }}$ microbalance. Evidence for the adsorption of heteropoly and isopoly anions on gold electrodes. J. Electroanal. Chem. 1995, 384, 155-169.

12 Kuhn, A.; Anson, F. C. Adsorption of monolayers of P2Mo180626- and deposition of multiple layers of Os(bpy)(3)(2+)-P2Mo18O626- on electrode surfaces. Langmuir 1996, 12, 5481-5488.

${ }^{13}$ Liu, J. ; Cheng, L.; Liu, B.; Dong, S; Covalent modification of a glassy carbon surface by 4-aminobenzoic acid and its application in fabrication of a polyoxometalates-consisting monolayer and multilayer films. Langmuir 2000, 16, 7471-7476.

${ }^{14}$ Errington, R. J.; Petkar, S. S.; Horrocks, B. R.; Houlton, A.; Lie, L. H.; Patole, S. N.; Covalent immobilization of a TiW5 polyoxometalate on derivatized silicon surfaces. Angew. Chem. Int. Edit. 2005, 44, 1254-1257.

${ }^{15}$ Song, Y. F.; McMillan, N.; Long, D. L.; Kane, S.; Malm, J.; Riehle, M. O.; Pradeep, C. P.; Gadegaard, N.; Cronin, L. Micropatterned surfaces with covalently grafted unsymmetrical polyoxometalate-hybrid clusters lead to selective cell adhesion. J. Am. Chem. Soc., 2009, 131, $1340-1341$.

${ }^{16}$ Mercier, D. ; Boujday, S. ; Annabi, C. ; Villanneau, R. ; Pradier, C. M. ; Proust, A. bifunctional polyoxometalates for planar gold surface, nanostructuration and protein immobilization. J. Phys. Chem. C 2012, 116, 13217-13224.

17 Joo, N.; Renaudineau, S.; Delapierre, G.; Bidan, G.; Chamoreau, L. M.; Thouvenot, R.; Gouzerh, P.; Proust, A. Organosilyl/-germyl polyoxotungstate hybrids for covalent grafting onto silicon surfaces: towards molecular memories. Chem-Eur J, 2010, 16, 5043-5051.

${ }^{18}$ Rinfray, C.; Izzet, G.; Pinson, J. ; Gam Derouich, S.; Combellas, C.; Kanoufi, F.; Proust, A. Electrografting of diazonium-functionalized polyoxometalates: synthesis, immobilisation and electron-transfer characterisation from glassy carbon. Chem. Eur. J., 2013, 19, 13838-13846.

${ }^{19}$ Huang, K.; Duclairoir, F.; Pro, T.; Buckley, J.; Marchand, G.; Martinez, E.; Marchon, J. C.; De Salvo, B.; Delapierre, G.; Vinet, F.; Ferrocene and porphyrin monolayers on Si(100) surfaces: preparation and effect of linker length on electron transfer. ChemPhysChem, 2009, 10, 963-971.

${ }^{20}$ Lindsey, J. S.; Bocian, D. F. Molecules for Charge-Based Information Storage. Accounts Chem Res 2011, 44, 638-650. 
$\overline{{ }^{21} \text { Roth, K. M.; Gryko, D. T.; Clausen, C.; Li, J. ; Lindsey, J. S.; Kuhr, W. G.; Bocian, D. F. }}$ Comparison of electron-transfer and charge-retention characteristics of porphyrin-containing self-assembled monolayers designed for molecular information storage. J. Phys. Chem. B 2002, 106, 8639-8648.

22 Fabre, B. Ferrocene-terminated monolayers covalently bound to hydrogen-terminated silicon surfaces. Toward the development of charge storage and communication devices. Acc. Chem. Res. 2010, 43, 1509-1518.

${ }^{23}$ Allongue, P.; Delamar, M. ; Desbat, B. ; Fagebaume, O. ; Hitmi, R. ; Pinson, J. ; Savéant, J. M. Covalent modification of carbon surfaces by aryl radicals generated from the electrochemical reduction of diazonium salts. J. Am. Chem. Soc. 1997, 119, 201-207.

${ }^{24}$ Bélanger, D.; Pinson, J. Electrografting: a powerful method for surface modification. Chem. Soc. Rev., 2011, 40, 3995-4048.

25 Chehimi, M. M., Aryl Diazonium Salts. New Coupling Agents in Polymer and Surface Science; Wiley-VCH:Weinheim, 2012.

${ }^{26}$ Jiang, D.-e.; Sumpter, B. G.; S. Dai, S. Structure and bonding between an aryl group and metal surfaces. J. Am. Chem. Soc., 2006, 126, 6030-6031.

${ }^{27}$ Laurentius, L.; Stoyanov, S. R.; Gusarov, S.; Kovalenko, A.; Du, R.B.; Lopinski, G. P.; McDermott, M. T. Diazonium-derived aryl films on gold nanoparticles: evidence for a carbon-gold covalent bond. ACS Nano, 2011, 5, 4219-4227.

${ }^{28}$ Toupin, M.; Bélanger, D. Thermal stability study of aryl modified carbon black by in situ generated diazonium salt. J. Phys. Chem. C, 2007, 111, 5394-5401.

29 D'Amours, M.; Bélanger, D.: Stability of substituted phenyl groups electrochemically grafted at carbon electrode surface. J.Phys.Chem.B, 2003, 107, 4811-4817.

${ }^{30}$ Li, Q.; Batchelor-McAuley, C.; Lawrence, N. S.; Hartshorne, R. S.; Compton, R. G. The synthesis and characterisation of controlled thin sub-monolayer films of 2-anthraquinonyl groups on graphite surfaces. New J. Chem. 2011, 35, 2462-2470.

${ }^{31}$ Kozub, B. R.; Henstridge, M. C.; Batchelor-McAuley, C.; Compton, R. G. Edge plane pyrolytic graphite electrode covalently modified with 2-anthraquinonyl groups: theory and experiment. ChemPhys Chem 2011, 12, 2806-2815.

${ }^{32}$ M. Ceccato, A. Bousquet, M. Hinge, S. U. Pedersen, and K.Daasbjerg, K. Using a mediating effect in the electroreduction of aryldiazonium salts to prepare conducting organic films of high thickness. Chem. Mater., 2011, 23, 1551. 
${ }^{33}$ Bousquet, A.; Ceccato, M.; Hinge, M.; Pedersen, S. U.; Daasbjerg, K. Redox grafting of diazotated anthraquinone as a means of forming thick conducting organic films. Langmuir, 2012, 28, 1267-1275.

34 Zhong, Y. L.; Ng, W.; Yang, J.-X.; Loh, K. P.; Electrostatically Self-Assembled Polyoxometalates on Molecular-Dye-Functionalized Diamond. J. Am. Chem. Soc. 2009, 131, 18293-18298.

35 Doppelt, P.; Hallais, G.; Pinson, J.; Podvorica, F.;Verneyre, S. Surface modification of conducting substrates. Existence of azo bonds in the structure of organic layers obtained from diazonium salts. Chem.Mater. 2007, 19, 4570-4575.

${ }^{36}$ Adenier, A.; Cabet-Deliry, E.; Lalot, T.; Pinson, J.; Podvorica, F. Attachment of polymers to organic moieties covalently bonded to iron surfaces. Chem. Mater. 2002, 14, 4576-4585.

${ }^{37}$ Anariba, F.; Viswanathan, U.; Bocian, D. F.;McCreery, R. L. Determination of the structure and orientation of organic molecules tethered to flat graphitic carbon by ATR-FT-IR and Raman spectroscopy. Anal.Chem. 2006, 78, 3104-3112.

38 Rocchioccioli-Deltcheff, C.; Fournier, M.; Franck, R.; Thouvenot R., Vibrational investigations of polyoxometalates. 2. Evidence for anions-anions interactions in molybdenum(VI) and tungsten(VI) compounds related to the Keggin structure. Inorg. Chem. 1983, 22, 207-216.

${ }^{39}$ Huang, W. L.; Todaro, L.; Yap, G. P. A.; Beer, R.; Francesconi, L. C.; Polenova, T. V-51 magic angle spinning NMR Spectroscopy of keggin anions [PVnW12-nO40] ((3+n)-): Effect of countercation and vanadium substitution on fine structure constants. J Am Chem Soc 2004, 126, 11564-11573.

${ }^{40}$ Vinther, J.; Iruthayaraj, J.; Gothelf, K.; Pedersen, S.U.; Daasbjerg, K. On electrogenerated acid-facilitated electrografting of aryltriazenes to create well-defined aryl-tethered films. Langmuir, 2013, 29, 5181-5189.

${ }^{41}$ O'Dea, J. J.; Osteryoung J. G. Characterization of quasi-reversible surface processes by square-wave voltammetry. Anal. Chem. 1993, 65, 3090-3097. 